San Jose State University

SJSU ScholarWorks

Master's Theses

Master's Theses and Graduate Research

1994

\title{
The effects of visual media usage and interpersonal communications on perceptions of the disabled population
}

\author{
Kathleen L. Guleff \\ San Jose State University
}

Follow this and additional works at: https://scholarworks.sjsu.edu/etd_theses

\section{Recommended Citation}

Guleff, Kathleen L., "The effects of visual media usage and interpersonal communications on perceptions of the disabled population" (1994). Master's Theses. 759.

DOI: https://doi.org/10.31979/etd.m6wj-wzer

https://scholarworks.sjsu.edu/etd_theses/759

This Thesis is brought to you for free and open access by the Master's Theses and Graduate Research at SJSU ScholarWorks. It has been accepted for inclusion in Master's Theses by an authorized administrator of SJSU ScholarWorks. For more information, please contact scholarworks@sjsu.edu. 


\section{INFORMATION TO USERS}

This manuscript has been reproduced from the microfilm master. UMI films the text directly from the original or copy submitted. Thus, some thesis and dissertation copies are in typewriter face, while others may be from any type of computer printer.

The quality of this reproduction is dependent upon the quality of the copy submitted. Broken or indistinct print, colored or poor quality illustrations and photographs, print bleedthrough, substandard margins, and improper alignment can adversely affect reproduction.

In the unlikely. event that the author did not send UMI a complete manuscript and there are missing pages, these will be noted. Also, if unauthorized copyright material had to be removed, a note will indicate the deletion.

Oversize materials (e.g., maps, drawings, charts) are reproduced by sectioning the original, beginning at the upper left-hand corner and continuing from left to right in equal sections with small overlaps. Each original is also photographed in one exposure and is included in reduced form at the back of the book.

Photographs included in the original manuscript have been reproduced xerographically in this copy. Higher quality $6 "$ " 9 9" black and white photographic prints are available for any photographs or illustrations appearing in this copy for an additional charge. Contact UMI directly to order.

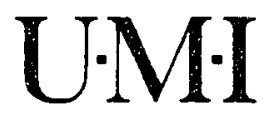

University Microfilms International

A Bell \& Howell Information Company

300 North Zeeb Road. Ann Arbor. MI 48106-1346 USA

313/761-4700 800/521-0600 

Order Number 1958183

The effects of visual media usage and interpersonal communications on perceptions of the disabled population

Guleff, Kathleen Louise, M.S.

San Jose State University, 1994

$\mathrm{U} \cdot \mathrm{M} \cdot \mathrm{I}$

300 N. Zeeb Rd.

Ann Arbor, MI 48106 


\title{
THE EFFECTS OF VISUAL MEDIA USAGE AND INTERPERSONAL COMMUNICATIONS ON PERCEPTIONS OF THE DISABLED POPULATION
}

\author{
A Thesis \\ Presented to \\ The Faculty of the School of Journalism \\ and Mass Communications
}

In Partial Fulfillment of the Requirements for the Degree Master of Science

by Kathleen L. Guleff May, 1994 Dr. David Grey 
- 1994

Kathleen L. Guleff

ALL RIGHTS RESERVED 
APPROVED FOR THE SCHOOL OF JOURNALISM AND MASS COMMUNICATIONS
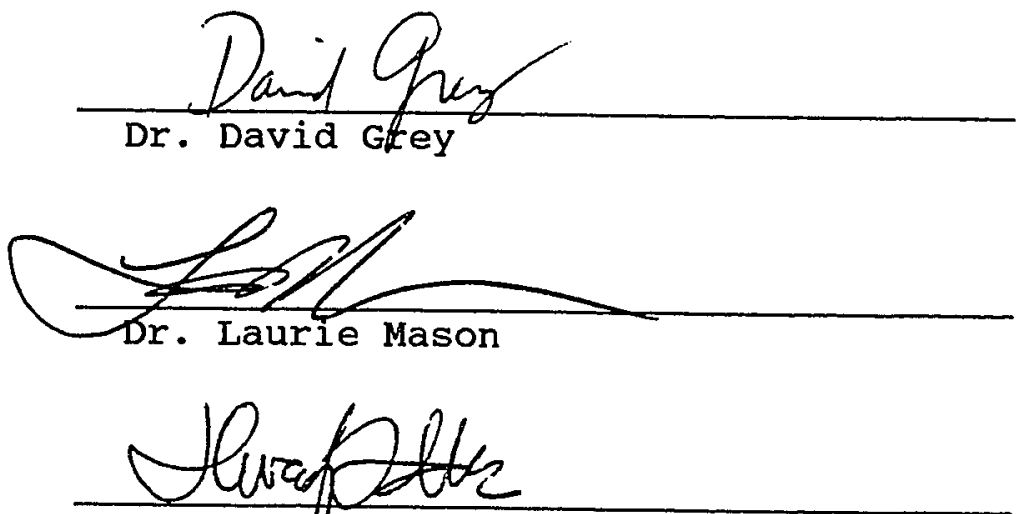

Dr. Harvfy Gotliffe

APPROVED FOR THE UNIVERSITY

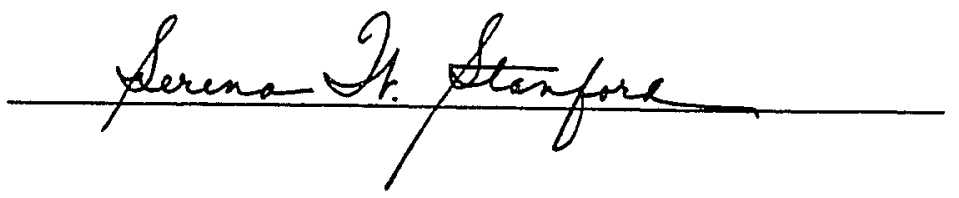


ABSTRACT

THE EFFECTS OF VISUAL MEDIA USAGE AND INTERPERSONAL COMMUNICATIONS ON PERCEPTIONS OF THE DISABLED POPULATION

By Kathleen L. Guleff

This thesis addresses the effect of media and interpersonal communications on perceptions about the disabled. In this study, 70 respondents were defined as heavy or light visual media consumers based on their selfreported habits, and also defined as having or not having a close relationship with a disabled person.

A Chi-square analysis indicated no significant difference when comparing knowledge and feelings scores between high and low media users or scores of high and low media users who were low in personal experience with disabled people.

Defining disability, defining an attitude as positive or negative, the archaic system of measuring heavy and light media users, and type of personal contact are discussed as contributing factors in the inadequacy of survey instruments to measure perceptions toward disabled people. 
TABLE OF CONTENTS

CHAPTER

PAGE

1

2

3

4

5
INTRODUCTION - . . . . . . . . . . . . . . . . 1
Perceptions of the Disabled Population . . 1 LITERATURE REVIEW AND HYPOTHESES . • • • • . 9

Media Exposure Effect on Knowledge . . . 12

Personal Experience Effect on Knowledge - 13

Media Exposure Effect on Feelings . . . . 14

Personal Experience Effect on Feelings - 15

METHODOLOGY • • • . • • . . . . . . 17

Questionnaire . . . . . . . . . 17

Procedure . . . . . . . . . . . 20

Call Contact Strategy . . . . . . . . 21

Scoring the Questionnaire . . . . . . 22

RESULTS • . • • • . • . . . . . . 32

DISCUSSION . . . . . . . . . . . . . 41

Pretests . . . . . . . . . . . 42

Summary • • • • . . . . . . . . 53

Conclusions .. . . . . . . . . . 61

REFERENCES - . . . . . . . . . . . . . . . 64 APPENDICES

Appendix A. . . . . . . . . . . . 70

Appendix B. . . . . . . . . . . . . 78 


\section{LIST OF TABLES}

TABLE

PAGE

1 .

Distribution of Knowledge Scores . . . . 32

2 .

Distribution of Feelings Scores . . . . . 32

3.

Hypothesis 1 Chi-Square Results . . . . 34

4.

Hypothesis 2 Chi-Square Results . . . . 36

5.

Hypothesis 3 Chi-Square Results . . . . 38

6.

Hypothesis 4 Chi-Square Results . . . . 40

7.

Average Knowledge Scores by Media Exposure

Pretest 1 . . . . . . . . . . . . . . . 44

8. Average Feelings Scores by Media Exposure

Pretest 1.................. . 44

9. Average Knowledge Scores with Low

Personal Experience

Pretest 1 . . . . . . . . . . . . . 45

10. Average Feelings Scores with Low

Personal Experience

Pretest 1... . . . . . . . . . . . 46 
CHAPTER 1

INTRODUCTION

Perceptions of the Disabled Population

Forty-three million Americans, approximately $17 \%$ of the population of the United States, are considered disabled according to the 1990 Americans with Disabilities Act (ADA). These Americans vary widely in severity and type of affliction as well as in identification with their disability, whether by self-assessment or assessment by others (Laplante, 1991).

Non-disabled citizens as well as 43 million disabled citizens in the United states are exposed to media communications that portray and define those things they may or may not have experienced themselves. Through this communication process, the media contribute to the opinion formation of its receivers (Noelle-Neumann, 1980).

Content analysis of media portrayals of the disabled population shows disabled people clustered under one of two stereotypes: mentally unstable characters and evil villains, or superheroes able to overcome great physical and emotional obstacles (Eberly, 1989). Whether depictions are negative or positive, common stereotypes are paternalistic and inaccurate (Clogston, 1992). These unified, repetitive themes contribute to the public's perception of persons with disabilities (Zola, 1985).

Disability is prominently portrayed in one or two 
feature film releases every year. In the last few years, motion pictures featuring disability have won numerous Academy Awards: Rain Man, My Left Foot, Children of a Lesser God, Coming Home, Charly, The Miracle Worker, Scent of a Woman, and The Piano.

The Wizard of $\mathrm{Oz}$ is an American institution shaping the way we think about tornadoes, scarecrows, and Kansas. It also helped shape the way many people think of individuals of exceptionally short stature. Munchkins were cute and childlike. But people with Achondroplasia, a type of dwarfism, do not have accelerated voices, do not have pointed ears or pointed feet, and are not any cuter than any other group of individuals (Egan, 1991).

Fictional television and motion pictures repeatedly use disability as a melodramatic plot device showing disability as a cause or consequence of wrongdoing. In the summer of 1992, Batman Returns earned $\$ 153$ million in seven weeks in movie theaters across the United States. Moviegoers were exposed to a character named Penguin. Because of his physical deformities, his family rejected him. He went on to rule havoc and evil on Gotham city. In 1991, millions of people saw Hook. The pirate's artificial limb came to stand for the evil of the villain, who derived his name from his disability.

The 1989 Academy Award-winning Rain Man received a 
great deal of widespread criticism among disabled groups because of its message that psychologically impaired individuals are probably better off in institutions (Nagler, 1990). Portrayals of mentally ill people in the media cover a wide range of non-defining parameters; from those who attend regular therapy sessions to institutionalized individuals. Those characters tend to lack social identity, many without family connections and without specific occupations. Studies (e.g., Wahl \& Roth, 1982) concluded that the portrayal of mental illness in the media is "a destructive one, encouraging the public to fear and to avoid the mentally ill as a dangerous breed apart" (p. 599).

The 1992 Academy Award winner, Scent of a Woman, reinforced the notion of near-magical powers that compensate for blindness: e.g., a blind man can tell the color of a woman's hair and can smell a good-looking woman at a great distance in a crowded restaurant (Bolte, 1993).

Blindness is one of the most frequently seen physical limitations on screen. Gary Lucchesi, producer of the 1993 movie titled Jennifer 8 (featuring Jennifer as a blind character) said, "Quite often a movie's success depends on having characters you can care about and a blind person is almost always someone to root for" (willins, 1994).

The American Foundation for the Blind keeps tabs on how blind people are portrayed in the media. When Jennifer 8 
was released, the organization angrily complained that the character should have been more self-sufficient, using public transportation and putting on her own makeup for instance.

The majority of media characterizations of blind people depict blindness as a condition of total darkness, when in reality, a clinical definition of blindness encompasses varying degrees of vision loss. A study conducted by the National Eye Institute (1990) disclosed that $90 \%$ of those defined as legally blind have some residual vision. On television and film, fewer than $6 \%$ of visually impaired characters have a degree of usable vision (Klobas, 1988).

Blind characters on-screen will sometimes touch the face of a person with whom they are speaking. This "face feeling" is seen on-screen as a prerequisite for establishing a relationship. "You have me at a disadvantage," says Faye Conners in Harry-O's "Second Sight," "I don't know what you look like." In Highway to Heaven's "The Monster," Rachel asks Julian, "Could I touch your face? - . it makes it easier to talk to someone if you know what they're like." A person who is blind does not, as a rule, feel faces (Klobas, 1988).

On September 25, 1991, an estimated 9.3 million people sat in their living room and watched a blind character named 
George in a situation comedy titled Good and Evil. George made his entrance in the first show by sweeping laboratory glassware off every surface he could reach with his wildly flailing cane. He introduced himself repeatedly to a coat rack. He groped across the body of another male character until persuaded of his masculinity. He walked into walls and crashed into doors. The producers insisted that this should not be offensive to blind people (Pierce, 1991). The National Federation of the Blind (NFB) states that most people identify a character like George as an accurate extension of a blind person trying to cope with the sighted world, adding to their inability to distinguish between the actual and the absurd where blindness is concerned (Cerone, 1991).

The National Federation of the Blind (NFB) bombarded the American Broadcasting Company ( $A B C)$ with letters and calls demanding Good and Evil be taken off the air because of the show's offensive treatment of blindness. It lodged complaints with network affiliates and sponsors. NFB protesters took to the streets with picket signs at $A B C$ headquarters in New York City and affiliates in Los Angeles, Chicago, Denver, and Washington demanding the show be removed from the air. After NFB's protests to sponsors, such as Aetna Life \& Casualty, Playtex, RTR Nabisco, and many more, $A B C$ canceled the sitcom. 
Each Labor Day, 100 million Americans tune into the Jerry Lewis Telethon. The public is exposed to Lewis' contention that "cripples are doomed to live as half a person," and "nature compensates for disabilities by giving the victim more strength and courage than other people." This program has so irritated many people with muscular dystrophy that two former MD poster kids have organized "Jerry's Orphans," a group that loudly protests the telethon and its negative impact on disabled people (Dyer, 1991). In 1992, Jerry's Orphans mounted demonstrations in 22 cities to oust Lewis, and have targeted the telethon's major corporate sponsors as part of a massive boycott (Guly, 1993).

Although telethons continue to raise funds, they also reinforce negative stereotypes and may immediately and lastingly affect perceptions and constructs about people with disabilities (Keller, Hallahan, McShane, Crowley \& Blandford, 1990).

Examples of television shows that portray disabled people on a regular basis are Wild, Wild West, Medical Center, and Ironside. The first of these was a western adventure series that consistently showed disabled persons to be sadistic criminals; the second was a medical drama that overplayed the psychological effects of traumatic disablement; the last was a detective drama that underplayed the effects of disability by largely ignoring its existence. 
Between syndicated reruns and cable television, these older television and film pictures are available for viewing almost daily.

The late 1980s witnessed the beginning of a more positive image of disabled people on television shows like $A B C$ 's Life Goes on, about a family with a child with Down Syndrome, as well as NBC's long-running series, L.A. Law, about a Los Angeles law firm that employs a mentally retarded messenger. The main character in Life Goes on, Corky, is portrayed by an actor with Down syndrome, advancing a further positive image.

Media attention is given to wheelchair athletes, amputees who run across country on one leg, and blind sailors who attempt to cross the Atlantic solo.

Terry Fox tried to run across North America on one leg and an artificial limb. He was forced to stop after logging some 3,339 miles because of a recurrence of cancer. Steve Fonyo, suffering from a disability almost identical to Fox's, made it all the way across Canada. Jim Dickson, who is legally blind, attempted to cross the Atlantic solo in a sailboat but because of bad weather and equipment failures was forced to turn back. All three stories received a unified picture of these events shared by newspapers, magazines, television networks, and other media. Individuals with disabilities have been highly critical of how the media 
covers such events (Krossel, 1988). Stories in the media focused on their struggle to overcome handicaps rather than their achievements as athletes.

The disability community continues to rail against the media. The National Organization of the Deaf (NOD) organized demonstrations of the movie Calendar Girl (February, 1993) before and after the movie was released. Calendar Girl features a profoundly deaf character portrayed by a hearing actor who NOD states does not accurately depict linguistically nor culturally a deaf person in the film. In the Calendar Girl demonstration kit available from the National Association of the Deaf, the organization states, "The deaf community of America will not tolerate misconceptions, stereotypes and assumptions regarding a deaf person to be portrayed in film."

Communication researchers (Shoemaker, 1985) using the concepts ethnicity and minority as variables, note that the media play a big role in the labeling perspective. Stereotypes, termed "conceptual shorthand" by linguist Edward Sapir, are intensified when they appear in the mass media and it is this association of disability with a deviant, stereotypical label that is most damaging. This association allows for disabled people, as a group, to be treated not in terms of what they are, but in terms of their images (Bogdan, Bilken, Shapiro \& Spelkoman, 1982). 


\section{Chapter 2}

\section{LITERATURE REVIEW AND HYPOTHESES}

Communication scholars have been historically interested in issues relating to the role of mass communication and the media in providing interpretations and social constructs about the world. As far back as 1894, scholars recognized that communication in general and the mass media in particular have a relationship to the social fabric of society (Wright, 1986). Public concerns raised about radio, motion pictures, and the press stimulated research on these topics. With the rapid growth of television in America in the late 1950s, studies examining the relationship between television viewing and attitude and perception have been conducted by researcher George Gerbner and his colleagues at the Annenberg School of Communication at the University of Pennsylvania.

Gerbner has maintained a regular monitoring activity of American television, developing a number of cultural indicators, the most widespread of which has become the violence profile (Gerbner, Gross, Eleey, Jackson-Beeck, Jeffries-Fox, \& Signorielli, 1977; Gerbner, Gross, Morgan, \& Signorielli, 1980). Gerbner's cultivation research deals with individuals' values and cognitions as influenced by their contact with society's culture as transferred by television.

Gerbner's strategy for investigating television effects 
upon perception of the real world began with the analysis of the television world. Gerbner et al. $(1977,1980)$ then constructed questions that had a television answer reflecting the television view of facts and a non-television answer, the answer from the real world.

Gerbner and his colleagues found that people steeped in the visual media world (heavy viewers) were more inclined to regard their environment in a way depicted on television than people less immersed (light viewers). Gerbner's analysis, over several years, showed consistent distortions of viewer's reality in respect to family, work and roles, aging, death, dying, education, violence, and crime. This evidence supports a view that high exposure to visual media leads to a belief in the view of the worid found in media messages. Cultivation theory portrays the media as offering uniform and relatively consensual versions of social reality, and audiences are acculturated accordingly (McQuail, 1987).

Researchers (Hawkins \& Pingree, 1981) have built on cultivation theory to suggest that exposure to racial, sexrole, and other stereotypes in the mass media contribute to the development of stereotyped beliefs, attitudes, and behavior. Others (Ball-Rokeach \& DeFleur, 1976) describe Gerbner's cultivation theory in terms of a dependency model of media effects. In complex societies, people rely on the 
media to provide information that is used to form basic attitudes, especially in areas that are ambiguous or are detached from their daily lives.

Scholarly investigations and criticism of the "cultivation process" include areas of concern on statistical controls and interpretation of Gerbner's cultivation findings. Specifically, Hirsch (1980) found that non-viewers in Gerbner's studies were overlooked and were just as likely to give the television answer as heavy media users.

It has been suggested that light and heavy viewers of visual media are different prior to - and aside from - the media. That is, heavy viewing is part of a complex syndrome that includes lower education, lower mobility, higher anxieties, and other age and sex-related characteristics (Gerbner \& Connolly, 1986).

One of the primary assumptions of cultivation is that visual media provides a relatively restricted set of choices for a unrestricted variety of interest and publics. This was especially true in the early formative years of the cultivation project when three commercial television networks offered relatively homogeneous fare and limited choices. Due to today's technology of manifold-channel capacity, video availability, cable television, and the remote control, critics point out that notions of the 
cultivation process are not as relevant as they once were (Bryant, 1986).

However, Gerbner's June 1993 statistical study, analyzing 19,645 roles in 1,371 media programs over a 10year period, found that women and minorities are dramatically underrepresented. Gerbner observed that, "Television seems to be stuck in a time warp of obsolete and damaging representations" (Gunther, 1993) regardless of channels, remote control and video availability.

Cultivation theory studies have focused on media portrayals of ethnic minorities and other groups, including women (wilson \& Gutierrez, 1985), but none has been done to link this theory with the disabled.

Media Exposure Effect on Knowledge

Studies found that heavy media viewers choose answers that reflect the media answer (patterned responses that match media content) rather than the non-media answer (empirical data) and other "real world" facts (Gerbner et al., 1977). Since media messages about groups of people are limited to a set of individuals, circumstances, and interpretations, these small representations are organized in memory by social group referents (Slater, 1990).

Given that the media often underrepresent and often inaccurately portray disability, high exposure to these representations can result in an accumulation of inaccurate 
knowledge about disabled people. Studies indicate that the impact of fiction messages about unfamiliar people has equal or greater impact on viewers than nonfiction messages (Slater, 1990). Applying cultivation theory - that heavy visual media usage leads to a belief in the view of the world found in media messages - coupled with evidence that the media message is often inaccurate and underrepresented concerning disability, the following hypothesis is proposed.

Hypothesis 1: Individuals with high levels of visual media exposure will be less accurate in knowledge about the disabled population than individuals with low levels of visual media exposure.

\section{Personal Experience Effect on Knowledge}

Calls for research (Brolley \& Anderson, 1990; National Organization on Disability, 1990) to determine whether media directly or indirectly influence the general public toward the disabled seemed to be answered with the commission of Louis Harris and Associates (1991) to conduct a survey of public attitudes toward people with disabilities. Harris reported, "Fersonal exposure to someone with a disability goes a long way in dispelling myths about disabled people" (p. 18). Harris, the disability community, and sociologists (Antonak, 1988; Yuker, 1988) note that increased contact with disabled people is associated with more accurate knowledge about disability.

In reconciling theories concerning media effects, it 
has been suggested that interpersonal communication is an important factor in overriding the media message and the power of the media is limited when this factor intervenes (Katz, 1980). When close interpersonal communications are absent, the amount of media exposure becomes relevant. Without intervention, the power of the media tends to be greater (Severin \& Tankard, 1988). Those who are less experienced with the real world (of disability) will be most affected by the dominant message of the media (Hawkins \& Pingree, 1981). Given the media often underrepresent and often inaccurately portray disability, coupled with the absence of personal experience mediation, hypothesis 2 is proposed.

Hypothesis 2: Among those with low personal experience with the disabled, individuals with high levels of visual media exposure will be less accurate in knowledge about the disabled population than individuals with low levels of media exposure.

\section{Media Exposure Effect on Feelings}

An ongoing problem for researchers in previous attitude assessment studies about disability have been that many nondisabled observers are reluctant to openly acknowledge their aversion to persons with disabilities (Hahn, 1988).

Even if all media images were positive, negative attitude formation in the majority population is likely to occur with disabiitty issues (Katz, 1980). Negative attitudes are the result of an attitudinal ambivalence about 
disabling conditions that create opposing emotions of anxiety about disability and compassion toward persons who are disabled. There is also a strong likelihood that attitudes about disabled people that are formed as a result of media exposure will be negative (Elliot, 1983; Byrd, 1989). Anxiety levels of the audience are considered because negative attitudes are more likely to be formed if the stimuli elicit anxiety. If most portrayals of persons with disability occur in dramas or emotion-packed stories, and these portrayals provide the only information for an audience about disability, then attitudes formed are likely to be negative (Miller, 1993).

If heavy visual media usage leads to a belief in the media messages about the world, coupled with evidence that the media message is often inaccurate and underrpresentative of disability, the following hypothesis is proposed.

Hypothesis 3: Individuals with high levels of visual media exposure will report more negative feelings about the disabled population than individuals with low levels of visual media exposure.

Personal Experience Effect on Feelings

Social science theorists report that prejudice is related to a lack of direct contact with the group. Consequently, the less contact with a particular group, the higher the expected amount of prejudice toward that group (Yuker, Block, \& Young, 1966; Yuker \& Block, 1979; Yuker, 
1988). The Harris poll, the disability community, and sociologists (Antonak, 1988; Yuker, 1988) note that increased contact with disabled people is associated with more favorable attitudes. The amount of exposure to visual media becomes irrelevant when personal experience is the factor of influence.

However, when close interpersonal communications are absent, the media provide the only information and thus, the reality about life with a disability (Miller, 1993). The amount of media exposure then becomes relevant. With the mass media expressing a dominant opinion, combined with a lack of interpersonal support for opposing views, heavy visual media exposure leads to a belief in the media messages represented. Since media messages about disabled people are often inaccurate and underrepresentative, the following hypothesis is proposed.

Hypothesis 4: Among those with low personal experience, individuals with high levels of media exposure will report more negative feelings about the disabled population than individuals with low levels of media exposure. 
Chapter 3

METHODOLOGY

Questionnaire

Two pretests were conducted to measure ambiguities in the language of the questionnaire arising from fears that politically correct use of words expressing disability had not been assimilated by the general public. The terminology "disabled" and "disability" is generally now preferred to "handicapped" and "handicap." In proposing a change in the name of the U.S. Senate subcommittee on the Handicapped to the U.S. Senate Subcommittee on Disability Policy, Senator Tom Harkin (D-Iowa) noted that the term handicapped has a negative connotation. The names of other important national organizations have also changed in recent years. The National Council on the Handicapped is now the National Council on Disability. The President's Committee on Employment of the Handicapped has become the President's Committee for the Employment of People with Disabilities.

In all cases, the questionnaire used the word disability and disabled. The first pretest consisted of 10 questions to measure knowledge and 10 questions to measure feelings. Knowledge and feelings questions were not arranged sequentially in the questionnaire. Four questions measured media exposure and one question measured personal experience with a disabled person.

The first pretest was taken at the De Anza Flea Market 
on November 7, 1992. Ten people agreed to answer the survey questions (Appendix A). The questionnaire began with the same opening paragraph that Harris used to survey 1,257 in 1991 and 1,253 people in 1993 to define public attitudes toward people with disabilities: "This survey is about people with physical or mental disabilities. I mean: people who are deaf or with very limited hearing; who have walking problems and use canes, crutches, or a wheelchair, or people with missing limbs; or who are blind or have a serious problem seeing; or who have serious speech problems. I am also including people with mental illness, mental retardation or serious learning disability" (Harris, 1991, 1993).

It took approximately 20 minutes for each respondent to complete a questionnaire. By observation, questions that involved a specific disability, like deafness, and blindness were answered quickly. Questions that used the words disabled and mentally disturbed seemed to take more thought and answers came more hesitantly. Two respondents in this group asked the researcher if people using drugs were considered mentally disabled. The researcher then repeated the opening statement. On observation, respondents tired after the 20th question and seemed less interested in participating in the media questions that were clustered at the end of the interview. 
The experience of the first pretest indicated the questionnaire was too long and required adjustments. Two knowledge questions were dropped: numbers 5 and 17 (see Appendix A), for failure to produce variable data. All respondents had answered accurately to these two questions by saying (a) it is not true that people with disabilities usually get cured or don't live very long and (b) you do not have to know braille to communicate with someone blind. Two feelings questions were dropped: numbers 7 and 10, (see Appendix A), for failure to produce variable data. AlI respondents agreed that they would sit right down if a waiter in a restaurant seated them next to a severely disabled person and all agreed that people with disabilities should live among the general population or at home with family. A shortened questionnaire was completed. (Appendix B) This shortened questionnaire had 21 questions instead of 25. The shortened questionnaire had eight questions to measure the dependent variable knowledge and eight questions to measure the dependent variable feelings. The number of media exposure and personal experience questions remained the same, four and one, respectively.

Using the shortened questionnaire, a second pretest was conducted on November 21, 1992, on an American Airlines flight from San Jose to Los Angeles. The first 10 people asked to participate in the survey agreed to fill out the 
questionnaire. This second pretest was taken privately by the individuals. All respondents completed the questionnaire in its entirety. No comments were written on the questionnaire or verbalized to the researcher. These questions (Appendix B) with no further revisions, were used to compile data for this survey.

\section{Procedure}

The data to test these hypotheses were derived from interviews of 70 adults in households throughout the san Jose area from November through December, 1992. Sixty respondents were interviewed by telephone, 10 were interviewed at the De Anza Flea Market during the first pretest. Respondents from the second pretest were not included because it was taken privately and respondents lived outside the geographic testing area.

The Pacific Bell 1992 white pages directory listed 158 prefixes in telephone area code (408) for San Jose, Santa Clara, Milpitas, Cupertino, and neighboring communities.

A Pascal computer program was written to replicate Waksberg's (1978) random-digit telephone dialing technique. This program used a random number generator to select the 158 prefixes and generate the last four digit suffixes randomly. This method was used for the 1978 California Disability Survey and the replication and enhancing of the 1990 California Disability Survey at the Berkeley Survey 
Research Center, University of California, Berkeley. This sampling method ensured inclusion of unlisted phone numbers and numbers added since the publication of the directory. Call Contact strategy

A computer program generated 1,200 telephone numbers in the first pass. Calls were placed in the order generated and were made Monday through Friday, primarily in the evening hours from 5 p.m. until 8:30 p.m. and additionally during daytime hours between noon and 1:30 p.m. Saturday and Sunday call contacts were attempted from 10 a.m. through 8:30 p.m. In order to attain the highest response rates, callbacks were made according to the following guidelines:

No answer/not-at-home. An initial call and then two callbacks to reach an adult member of the household. Callbacks were made on different days and at different times from initial calling time frame. If no success after this procedure, the number was discarded.

Busy signals. An initial call, a follow-up 15 minutes later, and two callbacks were made; after that, the number was discarded.

A total of 362 telephone numbers were dialed. In this sample frame, 130 telephone numbers were not in service or not working numbers; 29 were fax machines; 32 were businesses or institutions. Other numbers were discarded because of answering machines, hang-ups, language barriers, 
no adult members of a household, busy signals, no-answer numbers, and non-returned calls.

An adult member of a household who agreed to participate in the survey was assured of confidentiality. The survey then began with the same introduction used by Harris $(1991,1993$ ) in his field work, "This survey is about people with physical or mental disabilities. I mean: people who are deaf or with very limited hearing; who have walking problems and use canes, crutches, or a wheelchair, or people with missing limbs; or who are blind or have a serious problem seeing; or who have serious speech problems. I am also including people with mental illness, mental retardation, or serious learning disability." Scoring the questionnaire

Using the same 21 questions for all response compilations, an accurate response to a knowledge question added 1 point to the knowledge index; an inaccurate response added 0 to the index.

The eight knowledge questions in the survey began with question \#1: A random group of 100 Americans are gathered. How many in that group do you think are disabled? With $17 \%$ of the United States population considered disabled, the most accurate response was between 15-19 Americans in a group of 100 would be disabled. Respondents who said 15, $16,17,18$ or 19 of the 100 would be disabled, received a 
score of 1 for the accurate response. Respondents who said less than 15 or more than 19 of 100 Americans would be disabled, received a score of 0 for an inaccurate response. The next knowledge question in the survey was \#5: Do you believe that most crimes are committed by mentally disturbed people? Extensive studies of dangerousness have shown that crime rates among ex-mental patients are no higher than among corresponding persons in the general population (Townsend, 1979). Respondents who stated that they strongly believe or believe that most crimes are committed by mentally disturbed people were given a 0 score. This was considered an inaccurate response. Respondents who stated that they do not believe or strongly disbelieve that most crimes are committed by mentally disturbed people were given a score of 1 . This was considered an accurate response.

Question \#7 was a knowledge question. Do people with disabilities have more of a social life than other people? In 1985, Louis Harris and Associates conducted a survey of disabled Americans. Disabled Americans reported that their participation in social events was far less than the general population. Respondents who answered that people with disabilities have the same or somewhat less social life than other people were given a 0 score. This was considered an inaccurate response. Respondents who answered that people 
with disabilities have much less or a lot less social life than other people were given a score of 1 . This was considered an accurate response.

Question \#8 was a knowledge question. Do disabled people marry as often as those in the general population? According to most disability organizations, their membership has an equal marital status population as any other organized group membership. Respondents who answered no or probably not to the question of disabled people marrying as often as the general population were given a score of 0 . This was considered an inaccurate response. Respondents who answered probably yes or yes were given a score of 1 . This was considered an accurate response.

Question \#9 was a knowledge question. Do disabled people have children as often as those in the general population? According to disability organizations, their membership has an equal parental status population as any other organized group membership. Respondents who answered no or probably not to the question of disabled people having children as often as the general population were given a score of 0 . This was considered an inaccurate response. Respondents who answered probably yes or yes were given a score of 1 . This was considered an accurate response.

Question \#12 was a knowledge question. Can you name a famous disabled person who is not an entertainer? If the 
respondent could not name a famous disabled person who was not an entertainer they were given a 0 score. Respondents who named a famous disabled person who was not an entertainer, received a score of 1 .

Question \#13 was a knowledge question. Would you have to know sign language to communicate with someone deaf? Since communication with someone deaf can be done through handwriting as well as reading lips, respondents who said yes or probably yes that you would have to know sign language to communicate with someone deaf received a score of 0 . This was considered an incorrect response. Respondents who said that no or that you probably would not have to know sign language to communicate with someone deaf received a score of 1 . This was considered a correct response.

Question \#15 was a knowledge question. Would you agree or disagree that disabled employees miss more work than nondisabled employees? There are no data to indicate that disabled employees miss more work than non-disabled employees. Employers consistently rate their disabled employees equal or better than non-disabled employees. Respondents who agreed and strongly agreed that disabled employees miss more work than non-disabled employees received a 0 score. This was considered an inaccurate response. Respondents who disagreed and strongly disagreed 
that disabled employees miss more work than non-disabled employees received a score of 1 . This was considered an accurate response.

Total scores on knowledge accuracy for the questionnaire used in the survey ranged from 0 to $8 ; 0$ being the lowest and 8 the highest in knowledge. Knowledge scores were tabulated and the median point of distribution divided the scores in two parts, high and low. High knowledge would be an accumulation of points between 5 and 8 . Low would be accumulated points between 0 and 4 .

Positive and negative feelings were determined by eight questions. A positive or fairly positive response equaled 1 point. A negative or fairly negative response equaled 0 point. Using previous studies (Yuker et al. 1966, 1979) as a guide for interpretation of positive/negative attitudes toward disabled people, a positive response would be accepting disabled persons the same as everyone else; a negative response would be when disabled people were viewed as different and/or requiring special treatment.

Question \#2 began the feelings questions. How important is it that a lawyer in a courtroom be able to see? When a respondent accepts a disabled person the same as everyone else, this was considered a positive response. When respondents view disabled people as different and/or requiring special treatment, this was considered a negative 
response. Respondents who said it was not important or somewhat important received a score of 1 . This was considered a positive response. Respondents who said it was very important or essential that a lawyer in a courtroom be able to see, received a 0 score. This was considered a negative response.

Question \#3 was a feelings question. How important is it that a lawyer in a courtroom be able to hear? When a respondent accepts a disabled person the same as everyone else, this was considered a positive response. When respondents view disabled people as different and/or requixing special treatment, this was considered a negative response. Respondents who said it was not important or somewhat important that a lawyer be able to hear in a courtroom received a score of 1 . This was considered a positive response. Respondents who said it was very important or essential that a lawyer in a courtroom be able to hear received a 0 score. This was considered a negative response.

Question \#4 was a feelings question. Do you agree that people with disabilities should serve on juries? Respondents who strongly agreed or agreed that people with disabilities should serve on juries received a score of 1 . This was considered a positive response. Respondents who said they disagreed or strongly disagreed that people with 
disabilities should serve on juries were viewing disabled people differently and received 0 points. This was considered a negative response.

Question \#6 was a feelings question. If you were producing a show for television called "Dance Party U.S.A." would you invite blind people or people in wheelchairs to participate in the dancing? Respondents who said no or probably not were viewing people with disabilities differently and received a score of 0 . This was considered a negative response. Respondents who said yes or probably yes that they would invite people in wheelchairs or blind people to participate in the dancing were treating disabled people the same as others and received a score of 1 . This was considered a positive response.

Question \#10 was a feelings question. Is it harder for a disabled person to get a college degree? Respondents who said no or probably not were treating the disabled person the same as everyone else and received a score of 1 . This was considered a positive response. Respondents who answered probably yes or yes were treating disabled people differently and received a 0 score. This was considered a negative response.

Question \#11 was a feelings question. Two men attempt to climb a very high mountain. One man has a disability. The other man does not. Is the disabled man foolish, brave, 
daredevil, a hero? Is the non-disabled man foolish, brave, daredevil, a hero? Respondents who used the same term to describe the disabled man and the non-disabled man were treating them equally and received a score of 1 . This was considered a positive response. Those who chose one answer for the disabled man and a different answer for the nondisabled man were viewing them differently and received a score of 0 . This was considered a negative response. Question \#14 was a feelings question. Would you agree or disagree with this statement. Disabled people should be expected to work an 8-hour-a-day job. Respondents who strongly agreed and agreed that disabled people should be expected to work an 8-hour-a-day job were not viewing the disabled person differently from the general population and received a score of 1 . This was considered a positive response. Respondents who disagreed or strongly disagreed that disabled people should be expected to work an 8-hour-aday job were viewing disabled people differently and received a score of 0 . This was considered a negative response.

Question \#16 was a feelings question. Do you think a disabled person could do your job? Those who answered yes, received a score of 1 . This was a considered a positive response. Those who answered no, received a score of 0 . This was considered a negative response. Feelings scores 
were tabulated, and the median point of distribution divided the scores in two parts, high and low. High feelings were the accumulation of scores between 6 and 8 . Low feelings were the accumulation of scores between 0 and 5 . Gerbner's (1977) research separates heavy from light visual media users this way: more than four hours per day spent in watching visual media were considered high media users; less than four hours per day spent in this activity were low visual media users.

Using Gerbner's research as a guide, media usage was calculated by totaling television watching hours per week (Question 18), video watching (Question 19), and movie attendance (Question 20), then dividing the total by seven to achieve an average daily exposure to visual media.

An interval scale of $0-5$ was used to measure personal experience with disabled people. The closer the relationship, the higher the score. A respondent who did not know anyone with a disability was given a 0 score. If the disability relationship was based on acquaintance, a score of 1 was given. If the disability relationship was one of a co-worker, a score of 2 was given. If the relationship was based on friendship (not a co-worker), a score of 3 was given. A score of 4 was given if a respondent identified a disabled relative living outside his or her immediate household. Respondents who said that a 
member of their household (including self) was disabled scored a 5. If respondents identified themselves as knowing more than one disabled person in differing relationships, the highest scoring category was used for compilation.

A Chi-square analysis was used to test for statistical significance between heavy media and light media groups, as well as between heavy media and light media groups who had little or no personal experience with disabled people. 


\section{Chapter 4}

\section{RESULTS}

The 70 respondents were approximately evenly split by gender, with 33 (47\%) men and 37 (53\%) women. Experience with disabled people was split between 37 respondents with low personal experience (53\%) and 33 respondents having high personal experience (47\%). When measuring visual media exposure, 18 respondents were rated heavy visual media users, and 52 respondents were rated light visual media users.

The mode for knowledge scores was 4 (see Table 1). The mean for knowledge scores was 4 (see Table 1). The mode for feelings scores was 6 (see Table 2). The mean for feelings scores was 5 (see Table 2).

Table 1

Distribution of Knowledge Scores

Score Range

Frequency

$\begin{array}{lllllllll}0 & 1 & 2 & 3 & 4 & 5 & 6 & 7 & 8 \\ 2 & 3 & 5 & 10 & 21 & 12 & 9 & 5 & 3\end{array}$

Table 2

Distribution of Feelings scores

Score Range

Frequency

$\begin{array}{lllllllll}0 & 1 & 2 & 3 & 4 & 5 & 6 & 7 & 8 \\ 0 & 0 & 5 & 6 & 14 & 13 & 23 & 6 & 3\end{array}$


Hypothesis 1 examined the knowledge scores of all respondents by heavy and light media usage $(\underline{N}=70)$. Eighteen respondents were identified as heavy visual media users, and 52 were identified as light visual media users. Hypothesis 1 applied cultivation theory and social reality formation theory: What you know about the world comes from the media and/or personal experience. Receivers of heavy media interpretations of disability will incorporate biases in media content into their own constructions of reality and will be less accurate in their information about the disabled than light visual media users.

of the 18 heavy media respondents, seven were high in knowledge about disabled people. Of the 52 light media respondents, 22 were high in knowledge about disabled people. When comparing the accuracy of knowledge between heavy and light media users, a chi-square analysis produced no significant difference, $\mathrm{X}^{2}(1, \underline{\mathrm{N}}=70)=.07, \underline{p}>.05$ (Table $3)$, between knowledge scores of heavy visual media users and light visual media users and did not support hypothesis 1. For hypothesis 2, when close personal experience with disability is low or absent, the power of the media becomes greater for acquiring knowledge about disabled people. Those who are less experienced with the world of disability may adopt the media's message and acquire less accurate 
Table 3.

Analysis of knowledge scores between heavy media and light media respondents. (Hypothesis 1)

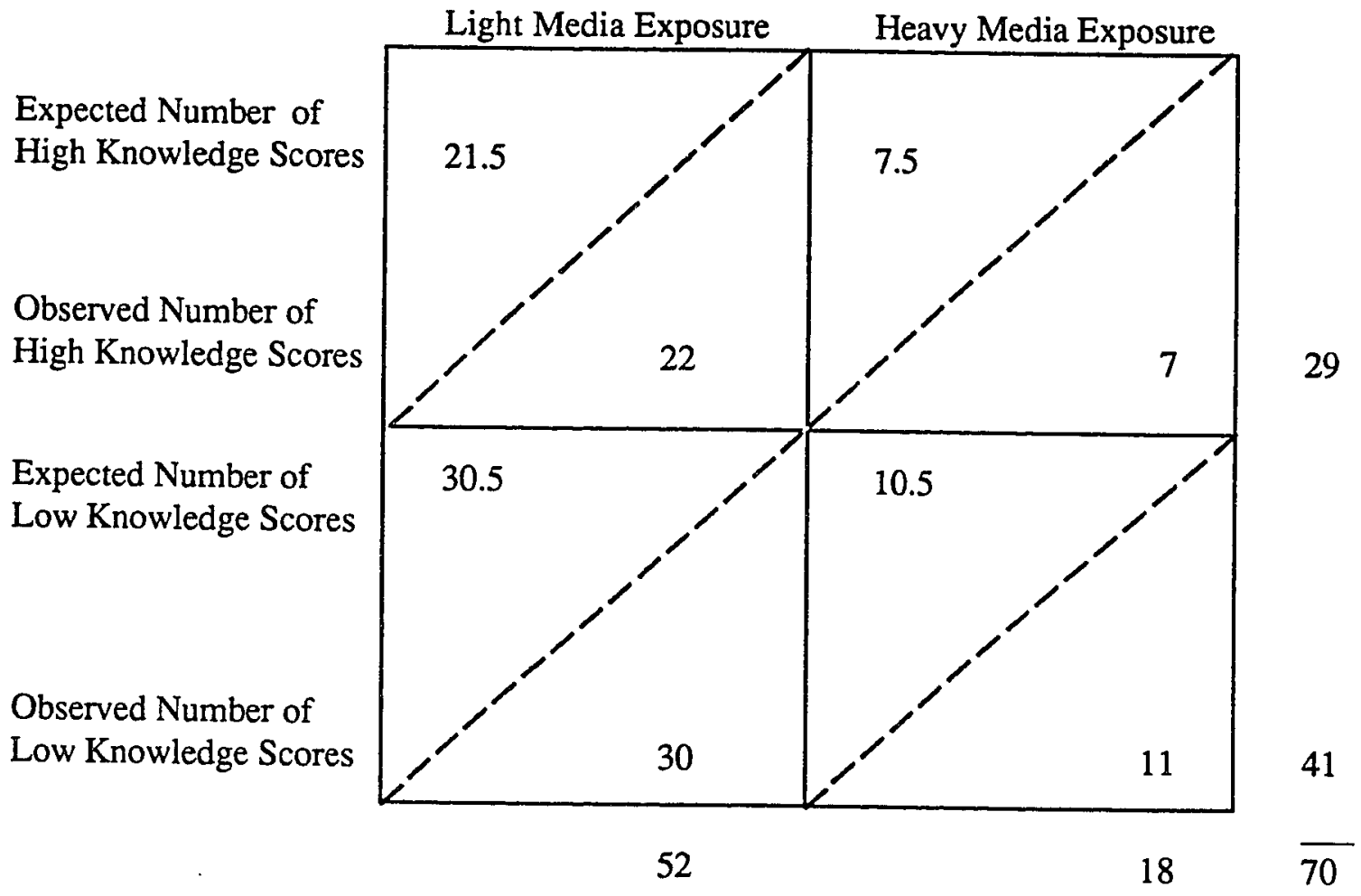


information about disabled people. Accurate knowledge about disabled people was tested by comparing knowledge scores of those with low personal experience and their heavy or light media usage. Of respondents identified as low in personal experience (37), 11 were identified as heavy media users, 26 were identified as light media users. Of those 11 identified as heavy media users, six were high in knowledge of disabled people. Of the 26 respondents identified as light media users, 10 were high in knowledge. A Chi-square analysis comparing knowledge scores of low personal experience respondents and their media use produced no significant difference, $x^{2}(1, \underline{n}=37)=.80, \underline{p}>.05$ (Table 4) and did not support hypothesis 2 .

Hypothesis 3, supported by cultivation theory, proposed that viewers incorporate biases in media content into their own construction of reality. Although few people publicly report negative feelings about the disabled (Kleck, 1968), research indicates the existence of negative attitudes toward people with disabilities (Weinberg, 1978; Wilkins \& Velicer, 1980; Ryan, 1981; Yuker, 1988).

By examining the positive and negative feeling scores of respondents $(\underline{N}=70)$, the effect of media exposure as a causing agent in attitude formation is explored. Of the 18 heavy media respondents, 10 reported negative feelings about disabled people. Of the 52 light media respondents, 26 
Table 4.

Analysis of knowledge scores between heavy and light media respondents who are low in personal experience. (Hypothesis 2)

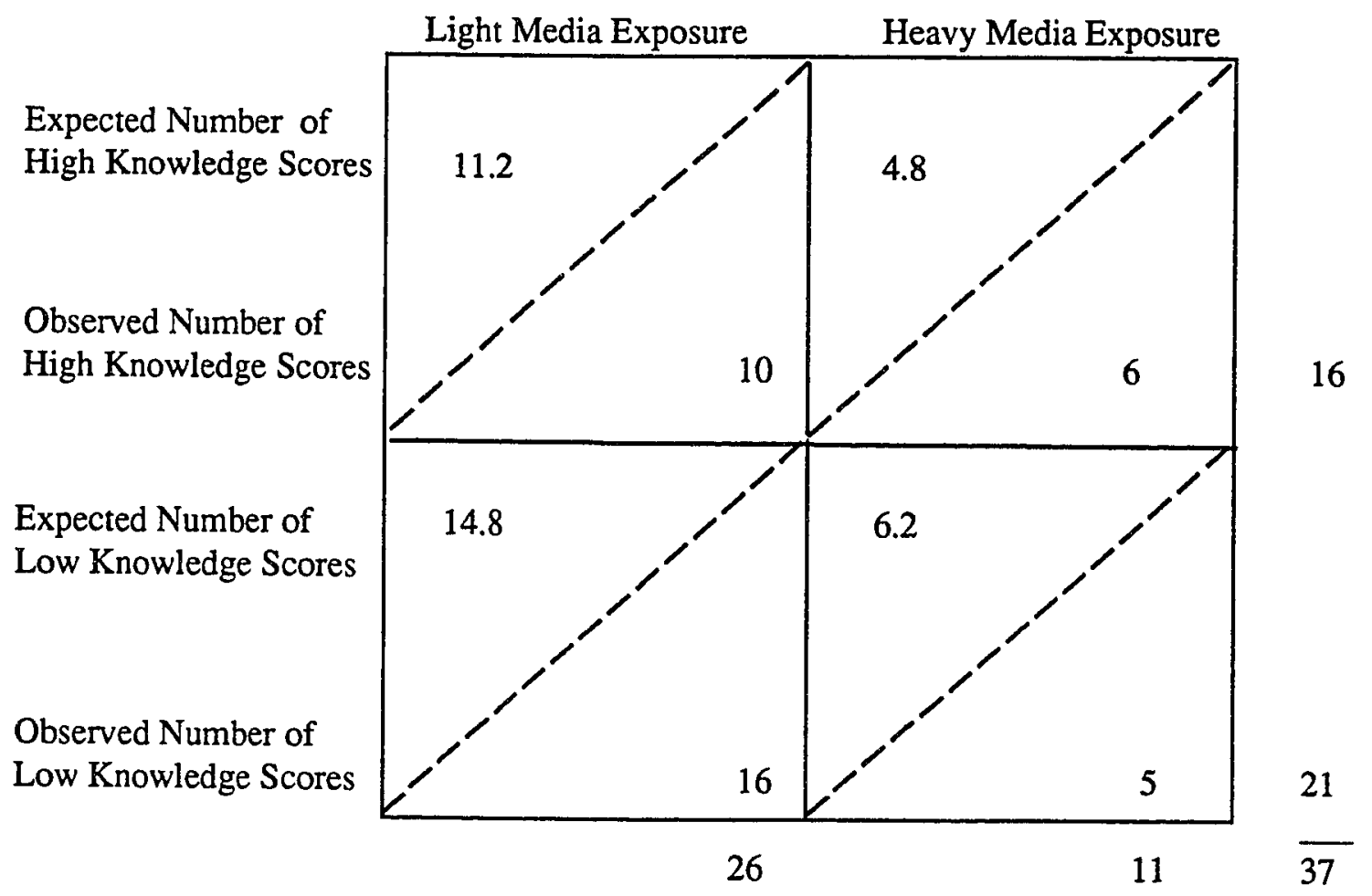


reported negative feelings about disabled people. A Chisquare analysis comparing positive and negative feeling scores by media usage produced no significant difference, $\mathrm{X}^{2}(1, \underline{\mathbf{N}}=70)=.16, \underline{p}>.05$ (Table 5) between heavy visual media users and light visual media users in their negative feelings about disabled people and did not support hypothesis 3 .

Because the amount of exposure to visual media becomes relevant in attitude formation in the absence of personal experience, and cultivation theory indicates viewers incorporate biases in media content into their own construction of reality, hypothesis 4 examined the feelings scores of respondents low in personal experience with disabled people and their heavy or light media exposure.

of the 37 low personal experience respondents, 16 reported positive feelings about disabled people and 21 reported negative feelings about disabled people. A feeling is considered positive if a disabled person is thought of in equal terms as that of a non-disabled person. A negative response would be when disabled people are viewed as different and/or requiring special treatment.

Of the 11 heavy media respondents who had low personal experience, five reported negative feelings and 
Table 5.

Analysis of feelings scores between heavy media and light media respondents. (Hypothesis 3)

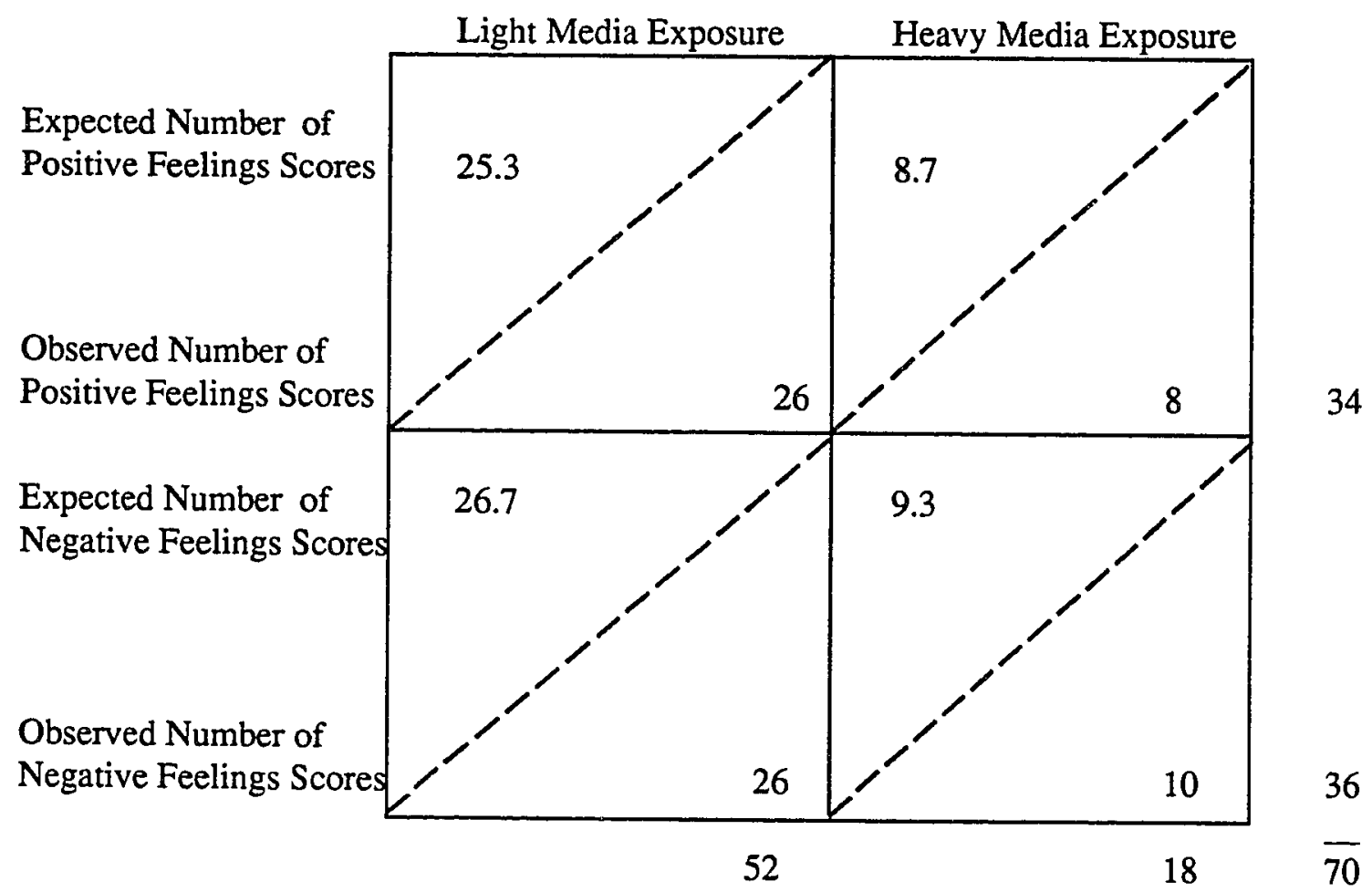


six reported positive feelings. Of the 26 light media respondents, 16 reported negative feelings and 10 reported positive feelings toward disabled people. In order for hypothesis 4 to be supported, heavy levels of media exposure and low personal experience with disabled people would result in more negative feelings. A Chi-square analysis comparing positive and negative feeling scores of those low in personal experience with the disabled and their media usage produced no significant difference, $x^{2}(1, \underline{n}=37)=$ $.80, \underline{p}>.05$ (Table 6) when comparing negative feelings about disabled people by light and heavy media usage. The chisquare analysis failed to support hypothesis 4. 
Table 6.

Analysis of feelings scores between heavy and light media respondents who are low in personal experience. (Hypothesis 4)

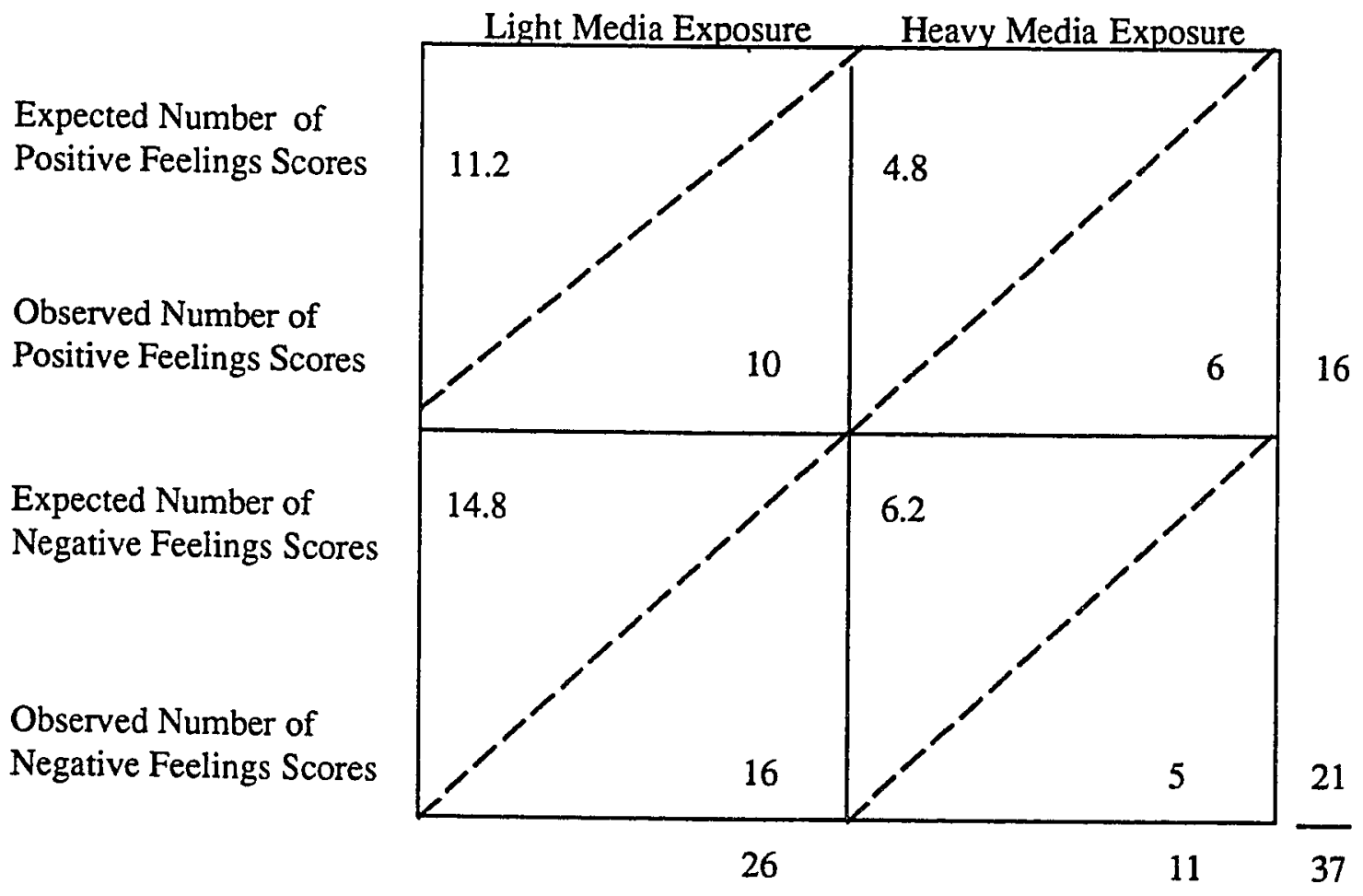




\section{Chapter 5}

\section{DISCUSSION}

This research found no support to indicate that individuals with high levels of visual media exposure have less knowledge or more negative feelings about disabled people than individuals who report low levels of visual media exposure.

When comparing the number of heavy media users with light media users, a methodological problem occurred. The number of heavy visual media users compared to the number of light visual media users was extremely disproportionate. When using the telephone sample of 60 respondents alone, only 14 heavy media users were identified, causing the Chisquare to produce extremely low cell sizes. To overcome this deficiency and enable the chi-square test to be carried out, respondents from the first pretest were included in the final tabulation. The inclusion of this group added four heavy media users and six light media users. The addition of four respondents who were heavy media users, enabled the Chi-square analysis to be carried out with appropriate values.

Questions asked in the main survey and in the first pretest were identical. Although the first pretest had four additional questions that were not used in the final survey, these were not tabulated in the final results. When measuring visual media exposure 18 respondents were 
identified as heavy users (more than four hours a day exposure) compared to 52 respondents who were rated light visual media users.

Comparing $26 \%$ of the sample size, heavy visual media users, to $74 \%$ of the sample size, light visual media users, caused the failure of the Chi-square analysis to produce significant differences for hypothesis 1 and 3 .

The same problem existed when testing hypothesis 2 and 4 using a sample size of 37 respondents who were low in personal experience with disabled people. For that sample, 11 respondents were identified heavy media users compared to 26 light media users. Comparing $30 \%$ of the sample size to $70 \%$ of the sample size for these hypotheses caused the failure of the Chi-square analysis to produce significant differences.

The scarcity of identified heavy media users was noted in the pretests, but seemed insignificant in the light of surveying a larger sample by telephone that would include people working odd shifts, elderly, disabled, and homemakers who traditionally are exposed to visual media in higher doses. Pretests

The pretests and final survey were scored and tabulated the same way. For all surveys, Gerbner's et al. (1977) research was used as a guide to calculate total media 
exposure. That is, more than four hours per day spent watching visual media were considered heavy media users; less than four hours per day spent in this activity were light visual media users. Adding hours per week, video watching, and movie attendance, and dividing the total by seven, achieved an average weekly exposure to visual media. For all surveys, an interval scale of $0-5$ was used to measure personal experience with disabled people. The closer the relationship, the higher the score. If respondents identified themselves as knowing more than one disabled person in differing relationships, the highest scoring category was used for compilation.

Positive and negative feelings were calculated the same for all surveys and modeled after the Attitudes Toward Disabled Persons (ATDP) scale. A positive response would be accepting disabled persons the same as everyone else; a negative response would be when disabled people were viewed as different and/or requiring special treatment.

The first pretest (Appendix A) had a total number of 10 respondents. Of these 10, six were light media users and four were heavy visual media users. The average knowledge scores of these respondents indicated that heavy media viewers were more knowledgeable about disabled people than light media viewers. The average scores (Table 7) indicated no support for hypothesis 1 . 
Table 7

Average Knowledge Scores by Media Exposure

$(\underline{N}=10)$ Pretest 1

Heavy Media(4) Light Media(6)

$\begin{array}{lll}\text { Knowledge } & 4.7 & 3.8\end{array}$

The average feelings scores of the 10 respondents by media exposure showed no support for hypothesis 3 (Table 8) in the first pretest. There were no differences in feelings scores when comparing respondents' average scores by their media exposure.

Hypothesis 3 predicted that heavy media users would have more negative feelings (lower scores) toward disabled people. This could not be supported.

Table 8

Average Feelings Scores by Media Exposure $(\underline{N}=10)$ Pretest 1 Heavy Media(4)

Light Media (6)

Feelings 5.0

5.0

Pretest 2 could not compare scores of light media users and heavy media users because all respondents were identified as light media users. The difficulty of identifying heavy media usage during pretest stages was 
attributed to the small pretest sample size as well as the public facilities of a flea market and an airport where the pretests were conducted. These locations might have excluded a large media exposure segment of the population.

All of these drawbacks were thought to be overcome with a larger sample size and a telephone survey that would give the surveyor the ability to tap into unrepresented respondents.

For testing hypotheses 2 and 4 in the first pretest, eight respondents were low in personal experience with disabled people. Calculating the average knowledge scores of these respondents by their media usage, showed no support for hypothesis 2 . When low personal experience with disability was identified, heavy media exposure respondents had equal knowledge about disabled people as light media exposure respondents (Table 9)

Table 9

Average Knowledge Scores of Respondents with Low Personal Experience ( $N=8)$ Pretest 1 Heavy Media(4) Light Media (4)

Knowledge 5.0 5.0

The first pretest indicated no support for hypothesis 4 when comparing the feelings scores of respondents with low 
personal experience and their heavy or light media usage. Heavy media users had the same score average when testing feelings as those identified as light media users (Table 10).

Table 10

Average Feelings Scores

of Respondents with Low Personal Experience ( $N=8$ ) Pretest 1 Heavy Media(4) Light Media(4)

$\begin{array}{lll}\text { Feelings } & 5.0 & 5.0\end{array}$

The second pretest precluded testing for all hypotheses because there were no identified heavy visual media users. All respondents (10) indicated light media exposure.

The weakness of not having enough identified heavy visual media users in both pretests were thought to be overcome in a larger sample size.

Unfortunately, that weakness was not overcome. The sample size of 70 indicated only 18 heavy media users. It is interesting to speculate why only 18 respondents were identified as heavy media viewers.

Since heavy visual media consumption is often associated with sedentary lifestyles, lower socio-economic levels, and non-intellectual pursuits, many people refuse to admit the hours spent in this activity. Time-use chroniclers 
say an astounding $40 \%$ of the average American's free time dissipates in front of the television (Baldwin, 1994) but Americans loathe to admit it.

A parallel to this denial of media exposure can be found in surveys that ask if anyone reads the National Enquirer. Few admit to reading it, but the National Enquirer sells between 9 and 12 million copies a week. People seem to be reluctant to admit that they spend time in a sedentary and non-interactive activity. This lack of accurate calculated sums of visual media exposure has haunted many media data collectors relying on self-reported methods. Even studies using technical equipment to monitor the media usage of households must cope with the difficulty of ascertaining exposure levels. Even when the media is being recorded as transmitted and received, the degree of receiver participation can be argued.

Using heavy and light viewing as an independent variable in studying media effects is subject to scrutiny. Not only for resulting methodological problems shown in this survey, but heavy versus light viewer differences are susceptible to an untested-third-variable explanation. Characteristics of heavy viewers that distinguish them from light viewers could easily account for differentials not explored. Although this survey explored the variable of personal contact with disabled people in addition to media 
usage, there were still a multitude of variables left untested.

Factors concerning the phenomenon of the telephone directly affect the validity of telephone surveys. Social factors related to the verbal and nonverbal behavior of persons contacted via telephone is one such factor. As telecommunications technology changes and telephone surveys continue to reach out to the public, there is a continuing evolution of the social norms of telephone-related behavior as these new technologies interact with human dispositions.

There is indication that a proportion of the public use their answering machines to screen calls they do not want to answer. As the cost of telephone answering machines dropped dramatically, more of the public used them. In 1992, market research estimates suggested that half of U.S. households have answering machines, with the proportion increasing annually. To the extent that any sizable proportion of the public routinely refuses to answer certain incoming calls, nonresponse in telephone surveys becomes an increasingly serious concern.

This survey contacted 362 telephone numbers. Of that number 111 were discarded because of answering machines, hang-ups, language barriers, no adult members of a household, busy signals, no-answer, and non-returned calls. The major portion of the non-reachable numbers were related 
to answering machines.

Another tradition that has previously worked to the advantage of telephone surveying is telephone protocol. That is, in a telephone conversation, it is the caller who determines the duration of the verbal interaction. The caller had a purpose for placing the call and courtesy dictates that the purpose should be fulfilled before the call is terminated. Increasingly, non-response suggests that this general norm is weakening. For this, the telemarketing industry has taken heavy criticism as many citizens do not differentiate between legitimate telephone surveys and telemarketing sales pitches. As fear of crime and concerns about the invasion of privacy grow, future telephone survey researchers will have to take these factors into consideration.

In addition to the lack of heavy media respondents, the difficulties of adequately conceptualizing the experience of disability (specific to this survey) can lead to misunderstandings in both collecting data and interpreting it.

The National Center for Health Statistics (NCHS) bases its disability measurement on activity limitations and chronic conditions. The Survey of Income and Program Participation is a longitudinal survey conducted by the Bureau of the census. Its data are based on the functional 
limitations model; that is, the difficulty in performing basic functions (seeing, hearing, speech, walking, lifting). In adults, disability is referred to only in terms of limitation or the inability to perform work.

The Bureau of Census does a monthly Current Population Survey. It deals mainly with labor force data by measuring those who have a health problem or disability that prevents working and limits the kind or amount of work that can be done.

The Census of Persons in Institutions and Group Quarters is part of the Census enumerating the number of people with work disabilities in institutions. Work disability is defined here as involving a condition (physical or mental) lasting six or more months that limits the amount of work a person can do.

The Social Security Administration conceptualizes and measures disability from initial pathology (such as birth defects) to residual impairments (a chronic health condition), to activity or mobility limitations, to disability in one or more societal roles.

The Americans with Disabilities Act (ADA) of 1990 includes in its definition of disability the following: orthopedic, visual, speech and hearing impairments, cerebral palsy, epilepsy, muscular dystrophy, multiple sclerosis, HIV infection, cancer, heart disease, diabetes, mental 
retardation, emotional illness, learning disabilities, drug addiction, and alcoholism. The ADA also adopted the supreme Court's interpretation of the definition of a disabled person to include a person with a contagious disease (School Board of Nassau County v. Arline, 480 U.S. 273, 1987).

Even among disabling conditions, disablement presents its own peculiar problems to the classifier. Many aspects of disablement are a matter of degree as well as of type. For example, blindness includes a definition of visual impairment as a limitation of one or more of the overall functions of the eye or visual system; visual disability (NCHS, 1975) is the inability to read newsprint even with glasses; a visual handicap is an inability to meet role expectations (Kirchner, 1988). Within that subset is another set. Legal blindness is based on clinical measures of visual acuity and of visual field (central visual acuity of $20 / 200$ or less in the better eye, with best correction). A person is also considered legally blind if the field of vision is restricted to 20 degrees or less (National Association for Visually Handicapped, 1990), but these individuals can have $20 / 20$ central vision enabling them to discern fine detail. A study conducted by the National Eye Institute disclosed that $90 \%$ of those defined as legally blind have some residual vision (NAVH, 1990). 
Various modes of conceptualizing disability are also related to special interests that gain or lose when one or another meaning is ascendant. An insurance carrier, lawyer, physician, judge, sociologist, economist, or injured party in a tort case all bring a different perspective to the meaning of disability.

For researchers, the conceptualization of disability is most often equated with limitations in performing socially expected roles and activities (Nagii, 1965, 1969, 1991), adding to the perspective of disability as a social construct (Ferguson, 1990) dependent on the interaction between the impairment and social forces.

Additionally, attitudes toward mentally ill individuals are distinct from attitudes toward other disabilities (Wisley \& Morgan, 1981). Studies indicate that a label of "mentally ill" activates preexisting beliefs and the most consistent elements of images of the mentally ill are violence and dangerousness. This is true of attitudes measured with abstract instruments as well as content analyses of media images (Townsend, 1990).

Complicating researchers ability to survey the public's perceptions toward disabled people is a sympathy effect that exists among interviewees who wish to avoid the appearance of rejection or prejudice toward the disabled. Blind people, people with orthopedic impairments, and people with 
epilepsy may not be seen by others as occupying common ground (Scotch, 1988). Likewise, those with "hidden disabilities" like epilepsy, diabetes, learning disabilities, and mental illness many not identify themselves or be identified as disabled.

With all the available definitions of disability, the opening statement of this survey replicated from Harris (1991, 1993) was inadequate to measure societal response to disabled people. "This survey is about people with physical or mental disabilities. I mean: people who are deaf or with very limited hearing; who have walking problems and use canes, crutches, or a wheelchair, or people with missing limbs; or who are blind or have a serious problem seeing; or who have serious speech problems. I am also including people with mental illness, mental retardation, or serious learning disability." This inadequacy should cast a serious pall over Harris' published survey.

\section{Summary}

The inadequacies of survey instruments when measuring knowledge and perceptions to disabled people are reinforced with this survey.

The lack of an adequate number of high media respondents resulted in a methodological problem for this survey. However, assessment of the data without media usage as a variable indicate that $59 \%$ of those surveyed were low 
in knowledge about disabled people and 53\% had negative feelings toward disabled people.

Overall, $90 \%$ of those interviewed agreed that people with disabilities should serve on juries. Likewise, many respondents thought that people who have disabilities might miss more work because of doctor appointments, therapy, and public transportation and they voiced those concerns to the researcher. Overall, $68 \%$ of respondents believe that disabled employees miss more work than non-disabled employees.

When the researcher asked about inviting blind people or people in wheelchairs to participate in the dancing for a television show titled, "Dance Party U.S.A." the majority of respondents first laughed or giggled then went on to say they would invite people in wheelchairs and blind people to participate. One respondent said he would invite only people in wheelchairs. Overall, $72 \%$ of respondents scored positively by saying they would invite disabled people to participate in the dancing.

Just $50 \%$ of those responding named a disabled person who was not an entertainer. Even though the question specifically asked for a non-entertainer many named stevie Wonder and Ray Charles. Those responses were not counted as accurate. George Wallace and Franklin D. Roosevelt were the most often mentioned as famous disabled people who were not 
entertainers.

Respondents had the most difficulty with question 14. Would you agree or disagree that disabled people should be expected to work an 8-hour-a-day job? All respondents wanted to be sympathetic. Many said that some disabled people can't work eight hours a day. Medication, fatigue, lack of jobs, and lack of public transportation were all factors that could prevent an 40-hour work week. Overall, 68\% believe that disabled people should work an 8-hour-a-day job.

When asked, "Do you think a disabled person could do your job?" all respondents said it would depend on the disability and then made a choice of answers. Overal1, 77\% of all respondents said yes, a disabled person could do their job. Those who said no, a disabled person could not do my job were scored 0 for that negative answer.

Was it really a negative response? If that respondent knew how a job could be performed by a disabled person, it is much more likely that they would agree it could be done. A hotel reservationist might say a blind person could not do his job because a blind person cannot see the computer screen. However, technology today allows a blind person to know what is on the screen through speech synthesis and the conversion of computer information into braille.

For many of the questions in this survey and Harris' it 
may be a gross generalization to score a negative response as a negative attitude when in fact with more information it would be a positive.

As discussed earlier, the wide range of disabilities and impairments, as well as hidden disabilities, cannot take in the whole spectrum that includes disablement. Harris noted in his 1991 survey conclusions, that the degree of discomfort in relation to people with disabilities varies according to the type of disability. One of the questions Harris (1991) asked in his questionnaire of 44 questions was, "How comfortable are you when you meet people who are blind, deaf, in a wheelchair, mentally retarded, mentally ill, facially disfigured, senile?" This question seemed inappropriate and certainly not all-encompassing so this study did not include it. His study found that at least twice as many people are uncomfortable with people with mental retardation, senility, facial disfigurement, or mental illness. Other studies (Yuker, 1977) reported more favorable public attitudes toward people with sensory handicaps than toward people who sometimes exhibit uncoordinated and unpredictable behavior, such as some cerebral palsied individuals. Adding to this phenomena of different disabilities triggering different attitudes is the documented study (Wisley \& Morgan, 1981) that attitudes toward mentally ill individuals are distinct from attitudes 
toward other disabilities. In large part, this is due to methodological problems revolving around what is meant by the term "mentally ill."

Research that measures disability as an all encompassing term is flawed. What Harris means by disabled, what the government considers disabled, what the medical community sees as disablement, as well as what disabled people think of disability, underscores the lack of cohesive meaning in the term disability. This underscores the need to refrain from viewing all disabled people as occupying a unitary social status. Although $82 \%$ of respondents in the survey knew someone disabled, this research did not explore the disability perspective of the respondent and made the erroneous assumption that disability is definable.

When interviewing Fred Fuller, director of Communications for the National Organization of Disability (NOD), the organization responsible for Harris' study, Fuller said, "What's happened in the very popular visual media is the depiction of disability in a more positive manner than in the past" (F. Fuller, personal communication, May 20, 1993). Given the legislation of the Americans with Disabilities Act (ADA) in 1990, the media in the past few years have given the disability community higher visibility adding to public awareness of disability.

According to Harris (1991), movies and television 
programs about people with disabilities are reaching most Americans. Whatever specific criticism there may be of individual programs and films, in the aggregate they are doing a great deal to increase public understanding of people with disabilities. Harris states, "These findings are mitigated by the fact that the people who are most likely to see these shows and movies are young and better educated" (p. 4).

The survey research for this project did not accumulate any demographic information about respondents other than gender. Collection of age and education information may have revealed certain tendencies but would not have addressed the problem of disability definition.

Although previous literature stated that close personal experience with groups led to more positive feelings and more accurate knowledge and could override the media message, this study did not find any statistical difference to support that.

Type of contact is an important determinant of attitudes. If this study had accumulated data relating to both type of contact and its extent, a fuller understanding of the relationship between contact and attitude would have been found. Attitudes as a result of contacts with disabled people and attitudes held by disabled people themselves (not separated in this survey) should be considered apart from a 
simple tabulation.

Personal experience with a disabled person could be based on the amount of daily time exposure spent with that person. It would also be helpful to know if the relationship was equal-status, whether social or professional. Types of equal-status contact increase positive attitudes and diminish prejudice, whereas limited or specialized types of interactions with disabled persons result in less positive or unchanged attitudes. The interval scale used for this survey scored relatives outside the immediate household a high of 4 . This scoring may be flawed. Even though a close blood relationship exists, the disabled relative may have not been seen for years or may only be known through family oral history. Likewise, a disabled friend who hasn't been seen in years would not have the same impact as a current co-worker who is seen every day during a work week.

One would predict that an individuals's attitude toward disabled persons is in part a function of specific experiences with one or a few disabled persons. One might expect that an individual whose only contact with the disabled was a positive or negative experience with one disabled individual might tend to generalize these attitudes to the disabled population as a whole. An individual whose initial attitude toward a group is negative will tend to 
become more negative with increased group contact.

The 70 respondent's scores, regardless of media usage, indicated that $53 \%$ reported negative feelings toward disabled people. The components of attitude formation toward disability involve both aesthetic and existential anxiety. Existential anxiety refers to the potential loss of functional capabilities by the non-disabled. The threat of permanent and debilitating disability with its resulting problems can even outrank the fear of death. Sometimes these concerns are evident, "there but for the grace of God (or luck or fate or other fundamental beliefs), go I." In a society that prizes personal autonomy, the apprehensions aroused from disability often seem overwhelming. Existential anxiety seems to involve a sense of personal identification with the position of a disabled person. That identification would be most acute in those who are familiar with disabled people.

The aesthetic anxiety aroused by the appearance of people with visible disabilities is a significant source of unfavorable attitudes toward disabled people (Bull, 1979). Most investigators assume that reactions to disabled individuals can be explained solely in terms of existential concerns. However, both existential anxiety and aesthetic anxiety are involved in unfavorable perceptions of people with disabilities (Hahn, 1988). For people who have close 
personal experience with disability, these anxieties may be heightened.

\section{Conclusions}

Disability is not a unifying concept. Any number of investigations about disability are flawed because of asking the wrong questions and of incorrect notions of the meaning of disability. The inability to define disability underscores the need to refrain from viewing all disabled people as occupying a unitary social status.

Reports that public attitudes are more favorable toward people with sensory handicaps than toward people who exhibit uncoordinated and unpredictable behavior, such as some cerebral palsied individuals, may be a gross oversimplification. It may well be that societal reactions toward a mildly afflicted cerebral palsied individual tend to be more positive than toward a deaf mute. There are almost no data on this problem, but it raises a question for future researchers to consider whether different types and degrees of disability are associated with distinctive social and emotional responses.

Future researchers should consider whether different types and degrees of disability are associated with distinctive social and emotional responses. Iimiting studies to a specific aspect of a disabling condition would ensure an equal baseline for data collection. There appears 
a pressing need to develop a new conceptual framework for appraisal of attitudes toward people with disabilities.

The flaws in all self-reported data seem even more apparent when researching disability. Previous research (Kleck, 1968) suggests that non-disabled people want to express attitudes that are acceptable to and respectful of disabled persons. The inability to draw an equal segment of the population who are heavy media consumers will continue to be problematic for researchers relying on self-reported data.

Gerbner's assessment of heavy media defined at four hours or more per day needs updating. Viewers see themselves as not being exposed to very much visual media on a daily basis. The daily criteria must be removed. Rather a cumulative picture of media exposure needs to be formulated, one that can tap into the unconscious as well as the conscious exposure to visual media.

Even perceptions of what constitutes positive attitudes toward persons with disabilities are not uniform. Positive attitudes have meant in previous research the dispensing with the special category or disability entirely, or promoting attitudes that defend the civil and social rights of disabled persons. Non-disabled people may actually be perceived by disabled people as expressing negative attitudes when in fact, the non-disabled are trying hard to 
express what they consider to be positive attitudes.

Research in the past has looked at interactions between disabled and non-disabled primarily, if not exclusively, from the point of view of the non-disabled interactant. Such methodology reinforces the view that disabled people are passive recipients of social interaction rather than active social negotiators in interactions with non-disabled people.

Further research needs to continue to evaluate media effects on those who are disabled. Questions concerning their identity and the effect of media in their life is an aspect of study that is sorely absent. Efforts directed toward integrating disabled people into the mainstream would benefit from an understanding of those socially induced conditions that help or hinder disabled people.

Increasing the numbers and conveying more positive images about disability in the media is but a first step. Researchers need to understand the deep-rootedness of myths and metaphors: how they have been supported in various cultural and historical milieu, how they have changed, and how they can or cannot be undone. Not only do the effects of these issues remain to be quantified but mass communication scholars face the challenge of producing a theoretical perspective on attitudes toward disabled people that reflect the new minority group model that has emerged. 


\section{References}


Antonak, R. F. (Ed.). (1988). The measurement of attitudes toward people with disabilities. Methods, psychometrics and scales. Springfield, IL: Charles C. Thomas

Baldwin, D. (i994, January 16). As busy as we wanna be. San Jose Mercury News, pp. 1C, 5C.

Ball-Rokeach, S. J., \& DeFleur, M. L. (1976). A dependency model of mass media effects. Communication Research, 3, 3-21.

Bogdan, R., Bilken, D. Shapiro, A. \& Spelkoman, D. (1982). The disabled: Media's monster. Social Policy, 13, 32-35.

Bolte, B. (1993, March). Hollywood and disability. Mainstream, pp. 25-32.

Brolley, D. Y., \& Anderson, S. C. (1990). Advertising and attitudes. In M. Nagler (Ed.), Perspectives on disability (pp. 147-150). Palo Alto, CA: Health Markets Research.

Bryant, J. (1986). The road most traveled: yet another cultivation critique. Journal of Broadcasting and Electronic Media, $30(2), 231-244$.

Bull, R. (1979). The psychological significance of facial deformity. In M. Cook \& G. Wilson (Eds.), Love and attraction: An international conference (pp. 21-25). Oxford: Permagon.

Byrd, E. K. (1989). A study of depiction of specific characteristics of characters with disability in film. Journal of Applied Rehabilitation Counseling 20 (2), 4345 .

Cerone, D. (1991). ABC drops good and evil. Braille Monitor, 12, 679-680.

Clogston, J.S. (1992, August). Coverage of persons with disabilities in prestige and high circulation dailies. Paper presented at the annual convention of the Association for Education in Journalism and Mass Communication, Montreal, Canada.

Dyer, B. (1991, September 1). Boycotter slams Lewis, MD telethon. San Jose Mercury News, pp. 1, 23. 
Eberly, S. (1989). Sticks, stones and stereotypes. Iowa Developmental Disabilities News, 12(2), 1, 3-4.

Egan, C. M. (1991, september 9). The seven dwarfs and I. Newsweek, pp. 8-9.

Elilott, T. R. (1983). Celluloid images of disability. American Rehabilitation 9(4), 12-15.

Ferguson, P. (1990). The social construction of mental retardation. In $M$. Nagler (Ed.), Perspectives on disability (pp. 203-210). Palo Alto, CA: Health Markets Research.

Gerbner, G., Gross, L., Eleey, M. F., Jackson-Beeck, M., Jeffries-Fox, S., \& Signorielli, N. (1977). Violence profile no. 8: Trends in network television drama and viewer conception of social reality. Philadelphia: Annenberg School of Communications.

Gerbner, G., Gross, L., Morgan, M. , \& Signorielli, M. (1980). The mainstreaming of America: Violence profile no. 11. Journal of Communication, 30, 10-29.

Gerbner, G. \& Connolly, K. (1986). Television as new religion. In M. Emery \& T. C. Smythe (Eds.), Readings in Mass Communication (pp.174-182). Dubuque, IA: Wm. C. Brown Company.

Guly, C. (1993, Fall). The means to a cure. Disability Today, pp. 23-28.

Gunther, M. (1993, June 16). Study says TV failing to diversify. San Jose Mercury News, p. $12 \mathrm{~A}$.

Hahn, H. (1988). The politics of physical differences: Disability and discrimination. Journal of Social Issues, $\underline{44}(1), 39-47$.

Harris, L. (1991). Survey and fieldwork on public attitudes toward people with disabilities. (study No. 912018) Washington, DC: National Organization on Disability.

Harris, L. (1993). Public opinion poll No. 931104. (pp. 133-156). Washington, DC: National Organization on Disability.

Hawkins, R., \& Pingree, S. (1981). Using television to construct social reality. Journal of Broadcasting, 
$\underline{25}(4), 347-363$.

Hirsch, P. M. (1980). The scary world of the nonviewer and other anomalies. Communication Research, 7(4), 403-456.

Katz, E. (1980). On conceptualizing media effects. In T. McCormack (Ed.), Studies in communication: Vol. 1 (pp. 119-141). Greenwich, CT: JAI Press.

Keller, C. Hallahan, D. McShane, E. Crowley, E. \& Blandford, B. (1990). The coverage of persons with disabilities in American newspapers. Journal of Special Education, 24, 271-282.

Kirchner, C. (1988). Data on blindness and visual impairment in the U.S. New York: American Foundation for the Blind.

Kleck, R. (1968). Physical stigma and nonverbal cues emitted in face-to-face interaction. Human Relations, 21, 19-28.

Klobas, L. E. (1988). Disability drama in television and film. North Carolina: McFarland \& Company, Inc.

Krossel, M. (1988) Handicapped heroes and the knee-jerk press. Columbia Journalism Review, May/June, 46-47.

LaPlante, M. P. (1991). The demographics of disability. In J. West (Ed.), The Americans with Disabilities Act: From policy to practice (pp. 56-75). New York: Milbank Memorial Fund.

McQuail, D. (1987). Mass communication theory (2nd ed.). London: Sage Publications.

Miller, L. (1993, August). More than stylebooks and political correctness: Societal effects of media coverage of persons with disabilities. Paper presented at the annual convention of the Association for Education in Journalism and Mass Communication, Kansas City, MO.

Nagi, S. Z. (1965). Some conceptual issues in disability and rehabilitation. In M. B. Sussman (Ed.), sociology and rehabilitation. Washington, DC: American Sociological Association.

Nagi, S. Z. (1969). Disability and rehabilitation. Columbus, OH: Ohio State University Press. 
Nagi, S. Z. (1991). Disability concepts revisited: Implications to prevention. In A. M. Pole and A. R. Tarlov (Eds.), Disability in America: Toward a national agenda for prevention. Appendix A. Washington, DC: National Academy Press.

Nagler, M. (Ed.). (1990). Perspectives on disability. Palo Alto, CA: Health Markets Research.

Noelle-Neumann, E. (1980). Mass media and social change in developed societies. In G. C. Wilhoit \& H. DeBock (Eds.), Mass communication review yearbook, Vol. 1, 657678. Beverly Hills, CA: Sage.

Pierce, B. (1991). No good for the blind in good and evil. Braille Monitor, 12, 654-683.

Ryan, K. (1981). Development differences in reactions to the physically disabled. Human Development, 24(4), 240256 .

Scotch, R. K. (1988). Disability as the basis for a social movement: Advocacy and the politics of definition. Journal of Social Issues, $44(1), 159-172$.

Severin, W. J., \& Tankard, J. W. (1988). Communication theories: Origins, methods, uses $(\mathrm{Ch} .20)$. New York: Longman.

Shoemaker, P. (1985). What do communication researchers really mean by ethnicity? Mass Communication Review, Fall, 12-17.

Slater, M. D. (1990). Processing social information in messages. Mass Communication Research, 17(3), 327-343.

Townsend, J. (1990). Stereotypes of mental illness: A comparison with ethnic stereotypes. In M. Nagler (Ed.), Perspectives on disability (pp. 102-117). Palo Alto, CA: Health Markets Research.

Wahl, O., \& Roth, R. (1982). Television images of mental illness: Results of a metropolitan Washington media watch. Journal of Broadcasting, 26(2), 599-605.

Waksberg, J. (1978). Sampling methods for random digit dialing. Journal of the American Statistical Association, 73, 40-46. 
Weinberg, N. (1978). Children's perceptions to orthopedic disability. In B. Bolton \& M. Jaques (Eds.), The rehabilitation client ( $\mathrm{pp} .49-55$ ). Baltimore: University Park Press.

Wilkins, J., \& Velicer, W. (1980). A semantic differential investigation of attitudes toward three stigmatized groups. Psychology in the schools, 17(3), 364-371.

Willens, M. (1994, February 2). Hollywood shows more insight. San Jose Mercury News, p. 3D.

Wilson, C. C., \& Gutierrez, F. (1985). Minorities and media. Beverly Hills: Sage Publications.

Wisley, D., \& Morgan, S. (1981). Children's ratings of peers presented as mentally retarded and physically handicapped. American Journal of Mental Deficiency, $\underline{86}(3), 281-286$.

Wright, C. R. (1986). Media, audience and social structure. Beverly Hilis, CA: Sage.

Yuker, H. E., Block, J. R., \& Young, J. H. (1966). The measurement of attitudes toward disabled persons. Albertson, NY: Human Resources Center.

Yuker, H. E., \& Block, J. R. (1979). Challenging barriers to change: Attitudes toward disabled. Albertson, NY: Human Resources Center.

Yuker, H. E. (1988). Attitudes toward persons with disabilities. New York: Springer Publishing.

Zola, I. K. (1985). Depictions of disability - metaphor, message, and medium in the media: a research and political agenda. The Social Science Journal, 22(4), 517. 
Appendix $A$

\section{Pretest 1 Questionnaire}

This survey is about people with physical or mental disabilities. I mean: people who are deaf or with very limited hearing; who have walking problems and use canes, crutches, or a wheelchair, or people with missing limbs; or who are blind or have a serious problem seeing; or who have serious speech problems. I am also including people with mental illness, mental retardation or serious learning disability.

(1) Q. A random group of 100 Americans are gathered. How many in that group do you think are disabled?

(2) Q. How important is it that a lawyer in a courtroom be able to see?

not important

somewhat important

very important

essential

(3) Q. How important is it that a lawyer in a courtroom be able to hear?

not important

somewhat important

very important

essential 
Appendix A (continued)

(4) Q. Do you agree that people with disabilities should serve on juries?

strongly agree

agree

disagree

strongly disagree

(5) Q. Is it true that people with disabilities either

recover or don't live very long?

- yes, it's true

no, it's not true

(6) Q. Do you believe that most crimes are committed by mentally disturbed people?

strongly believe

believe

do not believe

strongly disbelieve

(7) Q. A waiter in a restaurant seats your party next to a severely disabled person. Would you:

ask for another table

sit down,

but wait and see if another table is available

sit right down 
Appendix A (continued)

(8) Q. If you were producing a show for television called, "Dance Party U.S.A." would you invited blind people or people in wheelchairs to participate in the dancing?

No

Probably not

Probably yes

Yes

(9) Q. Do people with disabilities have more of a social

life than other people?

somewhat less

the same

much less

a lot less

(10) Q. Should people with disabilities live:

in a hospital

with other disabled people

among general population

at home with family

(11) Q. Do disabled people marry as often as the general population:

no

probably not

probably yes

yes 
Appendix A (continued)

(12) Q. Do disabled people have children as often as the general population?

no

probably not

probably yes

yes

(13) Q. Is it harder for a disabled person to get a college degree?

no

probably not

probably yes

yes

(14) Q. Two men attempt to climb a very high mountain. one man has a disability. The other man does not. Is the disabled man: (Pick one)

foolish

brave

daredevil

a hero

Is the non-disabled man: (Pick one)

foolish

brave

daredevil

a hero 
Appendix A (continued)

(15) Q. Can you name a famous disabled person who is not an entertainer? __ No _-

(16) Q. Would you have to know sign language to communicate with someone deaf?

no

probably not

probably yes

yes

(17) Q. Would you have to know braille to communicate with someone blind?

no

probably not

probably yes

yes

(18) Q. Would you agree or disagree with this statement. Disabled people should be expected to work an 8-hour day job.

strongly agree

agree

disagree

strongly disagree 
Appendix A (continued)

(19) Q. Would you agree or disagree that disabled employees miss more work then non-disabled employees?

strongly agree

agree

disagree

strongly disagree

(20) Q. Do you think a disabled person could do your job? - yes _ no

(21) Q. How many hours did you watch television yesterday excluding videos? Circle one:

0-2 hours $\quad 3-5$ hours $6-7$ hours over 8

(22) Q. How many hours a week do you usually watch

television excluding videos? Circle one:

0-10 hours $11-20$ hours $21-30$ hours over 30

(23) Q. How often do you watch movies from the video store?

Twice a week Once a week Once a month Never

(24) Q. How often do you go out to the movies?

Twice a week Once a week Once a month Never 
Appendix A (continued)

(25) Q. Do you know anyone with a disability?

- Yes ㄴ No

If yes, is this person (read list and circle one)

a member of your household

a relative outside your immediate household

a friend (not a co-worker)

a co-worker

an acquaintance 
Appendix B

Pretest 2 and Final survey Questionnaire

This survey is about people with physical or mental

disabilities. I mean: people who are deaf or with very

limited hearing; who have walking problems and use canes, crutches, or a wheelchair, or people with missing limbs; or who are blind or have a serious problem seeing; or who have serious speech problems. I am also including people with mental illness, mental retardation or serious learning disability.

(1) Q. A random group of 100 Americans are gathered. How many in that group do you think are disabled?

(2) Q. How important is it that a lawyer in a courtroom be able to see?

not important

somewhat important

very important

essential

(3) Q. How important is it that a lawyer in a courtroom be able to hear?

not important

somewhat important

very important

essential 
Appendix B (continued)

(4) Q. Do you agree that people with disabilities should serve on juries?

strongly agree

agree

disagree

strongly disagree

(5) Q. Do you believe that most crimes are committed by mentally disturbed people?

strongly believe

believe

do not believe

strongly disbelieve

(6) Q. If you were producing a show for television called, "Dance Party U.S.A." would you invited blind people or people in wheelchairs to participate in the dancing?

No

Probably not

Probably yes

Yes 
Appendix B (continued)

(7) Q. Do people with disabilities have more of a social life than other people?

somewhat less

the same

much less

a lot less

(8) Q. Do disabled people marry as often as the general population:

no

probably not

probably yes

yes

(9) Q. Do disabled people have children as often as the general population?

no

probably not

probably yes

Yes

(10) Q. Is it harder for a disabled person to get a college degree?

no

probably not

probably yes

yes 
Appendix B (continued)

(11) Q. Two men attempt to climb a very high mountain. One man has a disability. The other man does not. Is the disabled man: (Pick one)

foolish

brave

daredevil

a hero

Is the non-disabled man: (Pick one)

foolish

brave

daredevil

a hero

12) Q.Can you name a famous disabled person who is not an entertainer? Yes No

(13) Q. Would you have to know sign language to communicate with someone deaf?

no

probably not

probably yes

yes 
Appendix B (continued)

(14) Q. Would you agree or disagree with this statement. Disabled people should be expected to work an 8-hour day job.

strongly agree

agree

disagree

strongly disagree

(15) Q. Would you agree or disagree that disabled employees miss more work then non-disabled employees?

strongly agree

agree

disagree

strongly disagree

(16) Q. Do you think a disabled person could do your job? - yes _ no

(17) Q. How many hours did you watch television yesterday excluding videos?

0-2 hours $\quad 3-5$ hours $6-7$ hours over 8

(18) Q. How many hours a week do you usually watch television excluding videos?

0-10 hours 11-20 hours 21-30 hours over 30

(19) Q. How often do you watch movies from the video store? Twice a week Once a week Once a month Never 
Appendix B (continued)

(20) Q. How often do you go out to the movies?

Twice a week Once a week Once a month Never

(21) Q. Do you know anyone with a disability?

- yes - no

If yes, is this person (read list)

a member of your household

a relative outside your immediate household

a friend (not a co-worker)

a co-worker

an acquaintance

That completes the interview. Thank you very much. 